\title{
Correction to: Sexual harassment of students on public transport: an exploratory study in Lucknow, India
}

\author{
Kartikeya Tripathi $^{1} \cdot$ Hervé Borrion $^{1} \cdot$ Jyoti Belur $^{1}$
}

Published online: 19 June 2018

(C) Macmillan Publishers Ltd., part of Springer Nature 2018

\section{Correction to: Crime Prev Community Saf (2017) 19:240-250 https://doi.org/10.1057/s41300-017-0029-0}

The article Sexual harassment of students on public transport: an exploratory study in Lucknow, India written by K. Tripathi, H. Borrion and J. Belur was originally published electronically on the publisher's internet portal (currently SpringerLink) on 7 September 2017 without open access.

With the author(s)' decision to opt for Open Choice, the copyright of the article changed on June 2018 to () The Author(s) 2018, and the article is forthwith distributed under the terms of the Creative Commons Attribution 4.0 International License (http://creativecommons.org/licenses/by/4.0/), which permits use, duplication, adaptation, distribution and reproduction in any medium or format, as long as you give appropriate credit to the original author(s) and the source, provide a link to the Creative Commons license and indicate if changes were made.

The original article has been corrected.

The original article can be found online at https://doi.org/10.1057/s41300-017-0029-0.

Hervé Borrion

h.borrion@ucl.ac.uk

1 UCL Department of Security and Crime Science, 35 Tavistock Square, London WC1H 9EZ, $\mathrm{UK}$ 